\title{
Intrathecal morphine versus femoral nerve block for pain control after total knee arthroplasty: a meta-analysis
}

\author{
Yi Tang, Xu Tang, Qinghua Wei and Hui Zhang*
}

\begin{abstract}
Background: This meta-analysis aims to illustrate the efficacy and safety of intrathecal morphine (ITM) versus femoral nerve block (FNB) for pain control after total knee arthroplasty (TKA).

Methods: In April 2017, a systematic computer-based search was conducted in PubMed, EMBASE, Web of Science, Cochrane Database of Systematic Reviews, Cami Info. Inc., Casalini databases, EBSCO databases, Verlag database and Google database. Data on patients prepared for TKA surgery in studies that compared ITM versus FNB for pain control after TKA were collected. The main outcomes were the visual analogue scale (VAS) at 6, 12, 24, 48 and 72 and total morphine consumption at 12,24 and $48 \mathrm{~h}$. The secondary outcomes were complications that included postoperative nausea and vomiting (PONV) and itching. Stata 12.0 was used for pooling the data.

Results: Five clinical studies with a total of 225 patients (ITM group $=114$, FNB group $=111)$ were ultimately included in the meta-analysis. The results revealed that the ITM group was associated with a reduction of VAS at 6, 12, 24, 48 and $72 \mathrm{~h}$ and total morphine consumption at 12, 24 and $48 \mathrm{~h}$. There was no significant difference between the occurrences of PONV. However, the ITM group was associated with an increased occurrence of itching after TKA.

Conclusions: Some immediate analgesic efficacy and opioid-sparing effects were obtained with the administration of ITM when compared with FNB. The complications of itching in the ITM group were greater than in the FNB group. The sample size and the quality of the included studies were limited. A multi-centre RCT is needed to identify the optimal method for reaching maximum pain control after TKA.
\end{abstract}

Keywords: Intrathecal morphine, Total knee arthroplasty, Femoral nerve block, Meta-analysis

\section{Background}

Total knee arthroplasty (TKA) leads to considerable postoperative pain $[1,2]$. Ineffective pain control after TKA can cause many side effects [3]. Optimal pain control can not only decrease complications but also facilitate fast recovery during the immediate postoperative period [4]. Currently, a multimodal technique, a new concept, is accepted by most surgeons. Multimodal analgesia includes regional techniques, systemic opioids and preoperative administration gabapentin. Thus, femoral nerve block (FNB) and intrathecal morphine (ITM) are seldom used alone for the management of postoperative pain, though they are known to provide excellent analgesia [5]. Since the

\footnotetext{
* Correspondence: zhanghui201707@qq.com

Department of Orthopedics, People's Hospital of JianYang, No. 180, Yiyuan

Road, Jiancheng zhen, Jianyang, Sichuan Province, China
}

recommendation by the PROSPECT working group [6], FNB and ITM have become two common methods for postoperative analgesia management following TKA.

Regarding the efficacy and safety of ITM and FNB for pain control after TKA, there has yet to be a consensus. Recently, Li et al. [7] conducted a meta-analysis for this topic. However, several disadvantages existed in that meta-analysis. First it ignored important randomized controlled trials (RCTs), which may have had an important influence on the final results [8]. Furthermore, continuous FNB and single-shot FNB were not compared in a subgroup analysis. Thus, the purpose of this meta-analysis is to compare the efficacy and safety of ITM and FNB for pain control after TKA (Table 1). 
Table 1 The general characteristic of the included studies.

\begin{tabular}{|c|c|c|c|c|c|c|c|c|c|c|}
\hline \multirow[t]{2}{*}{ Study } & \multirow[t]{2}{*}{ Country } & \multicolumn{3}{|c|}{ FNB Group } & \multirow[t]{2}{*}{ Surgery } & \multicolumn{3}{|c|}{ ITM Group } & \multirow[t]{2}{*}{ Outcomes } & \multirow{2}{*}{$\begin{array}{l}\text { Follow- } \\
\text { up }\end{array}$} \\
\hline & & $\begin{array}{l}\text { No. of } \\
\text { patients }\end{array}$ & Method & Drug & & $\begin{array}{l}\text { No. of } \\
\text { patients }\end{array}$ & Dose & $\begin{array}{l}\text { Concomitant pain } \\
\text { management }\end{array}$ & & \\
\hline $\begin{array}{l}\text { Frassanito } \\
2010\end{array}$ & Italy & 26 & SFNB & $\begin{array}{l}\text { Ropivacaine } \\
0.75 \% 25 \mathrm{ml}\end{array}$ & TKA & 26 & $\begin{array}{l}\text { Hyperbaric } \\
\text { bupivacaine } \\
15 \mathrm{mg} \text { plus } \\
0.1 \mathrm{mg} \text { of } \\
\text { morphine } \\
\text { sulphate }\end{array}$ & $\begin{array}{l}\text { Paracetamol } 1 \mathrm{~g} \text { i.v. } \\
\text { four times daily and } \\
\text { intravenous. Ketorolac } \\
30 \mathrm{mg} 2 \text { times every } \\
24 \mathrm{~h}\end{array}$ & $1,2,3,4$ & $48 \mathrm{~h}$ \\
\hline $\begin{array}{l}\text { Mohamed } \\
2016\end{array}$ & Egypt & 20 & SFNB & $\begin{array}{l}\text { Hyperbaric bupivacaine } \\
15 \mathrm{mg}\end{array}$ & TKA & 20 & $\begin{array}{l}0.2 \mathrm{mg} \\
\text { morphine }\end{array}$ & PCA with morphine & $1,2,3,4$ & 3 month \\
\hline $\begin{array}{l}\text { Olive } \\
2015\end{array}$ & Australia & 27 & CFNB & $\begin{array}{l}20 \mathrm{ml} \text { bottle of } \\
0.5 \% \text { bupivacaine }\end{array}$ & TKA & 28 & $\begin{array}{l}0.5 \% \\
\text { bupivacaine } \\
3.5 \mathrm{ml} \text { plus } \\
0.175 \mathrm{mg} \\
\text { morphine }\end{array}$ & $\begin{array}{l}0.5 \% \text { bupivacaine } \\
3.5 \mathrm{~mL}\end{array}$ & $1,2,3,4$ & 1 year \\
\hline Sites 2004 & USA & 20 & SFNB & $\begin{array}{l}40 \mathrm{~mL} \text { of } 0.5 \% \\
\text { ropivacaine with } 75 \mathrm{mg} \\
\text { of clonidine and } 5 \mathrm{mg} / \mathrm{mL} \\
\text { of epinephrine }\end{array}$ & TKA & 20 & $\begin{array}{l}0.25 \mathrm{mg} \\
\text { morphine } \\
\text { and } 15 \mathrm{mg} \\
\text { hyperbaric } \\
\text { bupivacaine }\end{array}$ & $\begin{array}{l}30 \mathrm{mg} \text { ketorolac IV } \\
\text { every } 6 \mathrm{~h}\end{array}$ & $1,2,3,4$ & $48 \mathrm{~h}$ \\
\hline $\begin{array}{l}\text { Tarkkila } \\
1998\end{array}$ & India & 18 & CFNB & $\begin{array}{l}0.25 \% \text { bupivacaine at a } \\
\text { rate of } 0.1 \mathrm{~mL} \mathrm{~kg} 1 \mathrm{~h} 1\end{array}$ & TKA & 20 & $\begin{array}{l}0.3 \mathrm{mg} \\
\text { morphine } \\
\text { mixed with } \\
\text { bupivacaine }\end{array}$ & $\begin{array}{l}\text { Oxycodone } 0.1- \\
0.14 \mathrm{mg} / \mathrm{kg}\end{array}$ & $1,2,3,4$ & $48 \mathrm{~h}$ \\
\hline
\end{tabular}

FNB femoral nerve block, ITM intrathecal morphine, TKA total knee arthroplasty

\section{Methods}

This systematic review was reported according to the preferred reporting items for systematic reviews and meta-analyses (PRISMA) guidelines [9].

\section{Search strategies}

The following databases were searched in September 2016 without restrictions on location or publication types: PubMed (1950-April 2017), EMBASE (1974April 2017), the Cochrane Library (April 2017, Issue 4), Cami info. Lnc (1950-April 2017), Casalini databases (1950-April 2017), EBSCO databases (1950-April 2017), Verlag database (1950-April 2017) and Google database (1950-April 2017). The Mesh terms and their combinations used in the search were as follows: "analgesia" OR "pain management" OR "anaesthetic agents" OR "total knee arthroplasty" OR "total knee replacement" OR "TKA" OR "TKR" OR “"Arthroplasty, Replacement, Knee"[Mesh]" AND "intrathecal morphine" OR "femoral nerve block". The reference lists of related reviews and original articles were searched for any relevant studies, including RCTs involving adult humans. There was no language restriction for this meta-analysis. When multiple reports describing the same sample were published, the most recent or complete report was used. This meta-analysis gathered data from published articles, and thus, no ethics approval was necessary for this article.

\section{Inclusion criteria and study selection}

Patients: patients prepared for primary unilateral TKA; Intervention: use ITM as an intervention group; Comparison: use FNB as a comparison group; Outcomes: VAS at $6,12,24,48$ and $72 \mathrm{~h}$, total morphine consumption at 12,24 and 48 , and related complications (postoperative nausea and vomiting (PONV) and itching); Study design: RCTs (Fig. 1).

Two independent reviewers screened the title and abstracts of the identified studies after removing the duplicates from the search results. Any disagreements about the inclusion or exclusion of a study were solved through discussion or consultation with an expert (skilled in pain control and TKA). The reliability of the study selection was determined by Cohen's kappa test, and the acceptable threshold value was set at $0.61[6,7]$.

\section{Data abstraction and quality assessment}

A specific extraction was conducted to collect data in a pre-generated standard Microsoft Excel (Microsoft Corporation, Redmond, Washington, USA) file. The items extracted from relevant studies were as follows: first author and publication year, country, sample size of the intervention and control groups, preoperative and postoperative doses, timing and frequency and the total dose of gabapentin per number of days and follow-ups. Abstracted and recorded in the spreadsheet were outcomes such as the 


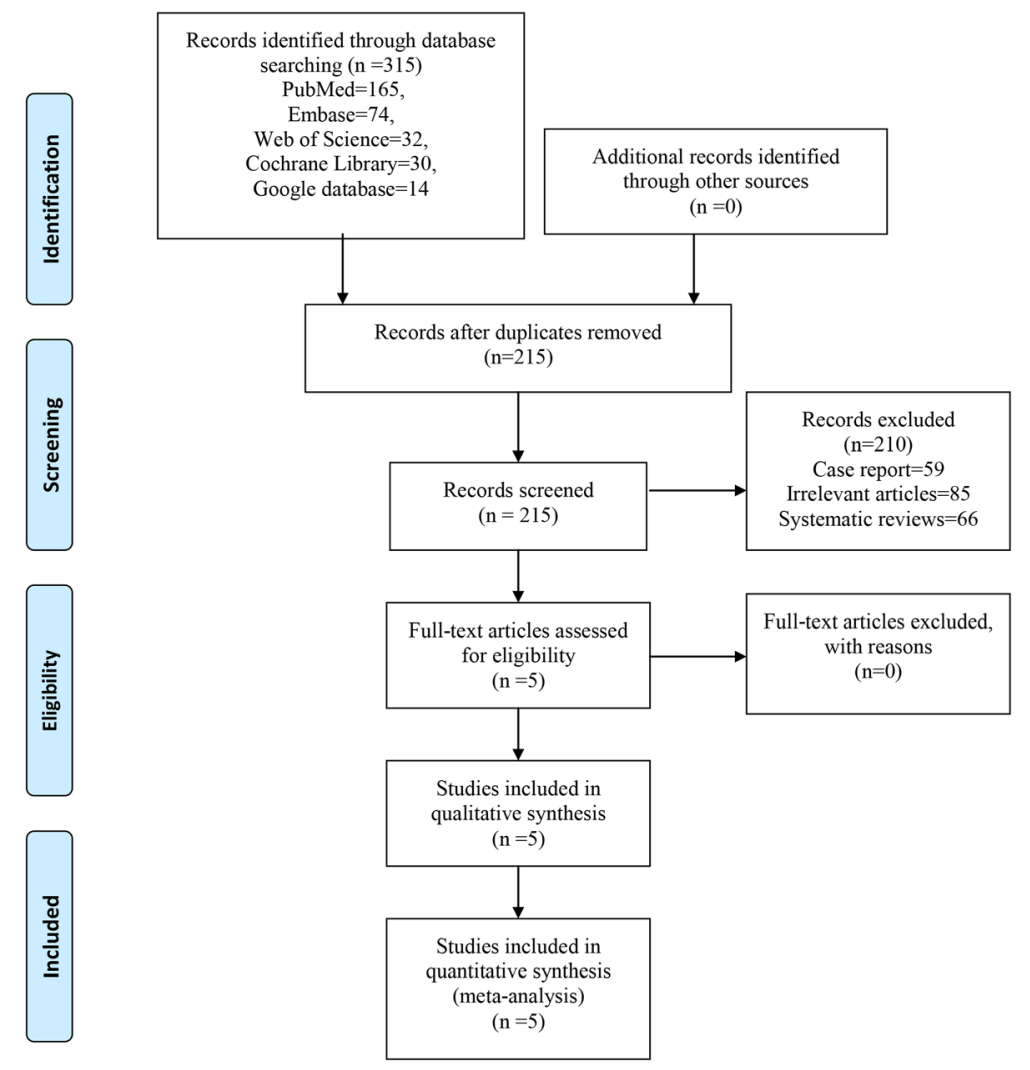

Fig. 1 Flowchart of study search and inclusion criteria

VAS at $6,12,24,48$ and $72 \mathrm{~h}$; total morphine consumption at 12, 24 and $48 \mathrm{~h}$; and related complications (PONV and itching). Postoperative pain intensity was measured using a 110 -point VAS ( $0=$ no pain and $100=$ extreme pain). When the numerical rating scale (NRS) was reported, it was converted to a VAS. Additionally, a 10point VAS was converted to a 100-point VAS [10]. Data in other forms (i.e. median, interquartile range, and mean $\pm 95 \%$ confidence interval $(\mathrm{CI})$ ) were converted to the mean \pm standard deviation (SD) according to the Cochrane Handbook [11]. If the data were not reported numerically, we extracted these data using the "GetData Graph Digitizer" software from the published figures. All the data were extracted by two independent reviewers, and disagreements were resolved through discussion.

The quality of all included trials was independently assessed by two reviewers on the basis of the Cochrane Handbook for Systematic Reviews of Interventions, version 5.1.0 (http://training.cochrane.org/handbook/) [11]. A total of seven domains were used to assess the overall quality: random sequence generation, allocation concealment, blinding of participant and personnel, blinding of outcome assessment, incomplete outcome data, selective reporting and other bias. Each domain was measured as low bias, unclear bias or high bias.

\section{Outcome measures and statistical analysis}

Continuous outcomes (VAS at 6, 12, 24, 48 and $72 \mathrm{~h}$ and total morphine consumption at 12, 24 and $48 \mathrm{~h}$ ) were expressed as weighted mean differences (WMD) with 95\% CI. Dichotomous outcomes (the occurrence of PONV and itching) were expressed as a risk ratio (RR) with 95\% CI. Statistical significance was set at $P<0.05$ to summarize the findings across the trials. Variables in the metaanalysis were calculated using Stata software, version 12.0 (Stata Corp., College Station, TX). Statistical heterogeneity was evaluated using the chi-square test and the $I^{2}$ statistic. When there was no statistical evidence of heterogeneity $\left(I^{2}<50 \%, P>0.1\right)$, a fixed-effects model was adopted; otherwise, a random-effects model was chosen. Publication bias was tested using funnel plots. Publication bias was visually assessed using funnel plots and was quantitatively assessed using Begg's test. Subgroup analysis was conducted according to the type of continuous FNB (CFNB) or single shot FNB (SFNB). We did not perform the publication bias since the numbers were less than ten.

\section{Results}

Search results and quality assessment

In the initial search, a total of 386 studies were identified from the electronic databases (PubMed $=165$, EMBASE $=74$, 
Web of Science $=32$, Cochrane Database of Systematic Reviews $=30$, Google database $=14$ ). Then, all papers were input into Endnote X7 (Thomson Reuters Corp., USA) software for the removal of duplicate papers. A total of 308 papers were reviewed, and 209 papers were removed according to the inclusion criteria at abstract and title levels. Ultimately, five clinical studies with 225 patients (ITM group $=114$, FNB group $=111$ ) were included in this metaanalysis $[8,12-15]$.

The quality assessment of the included studies is summarized in Figs. 2 and 3. All studies describe the random sequence generation procedure. Two studies did not describe allocation concealment and the blinding of participants and personnel and thus had an unclear risk of bias. The rest of the items all had a low risk of bias. The overall kappa value for the evaluation of the risk of bias of included RCTs was 0.763 , indicating that the agreement between the two reviewers was acceptable.

\section{VAS at $6,12,24,48$ and $72 \mathrm{~h}$}

Postoperative VAS scores at $6 \mathrm{~h}$ were reported in three studies, and the pooled results indicated that ITM can decrease VAS scores at $6 \mathrm{~h}(\mathrm{WMD}=-3.04,95 \% \mathrm{CI}-5.19$,

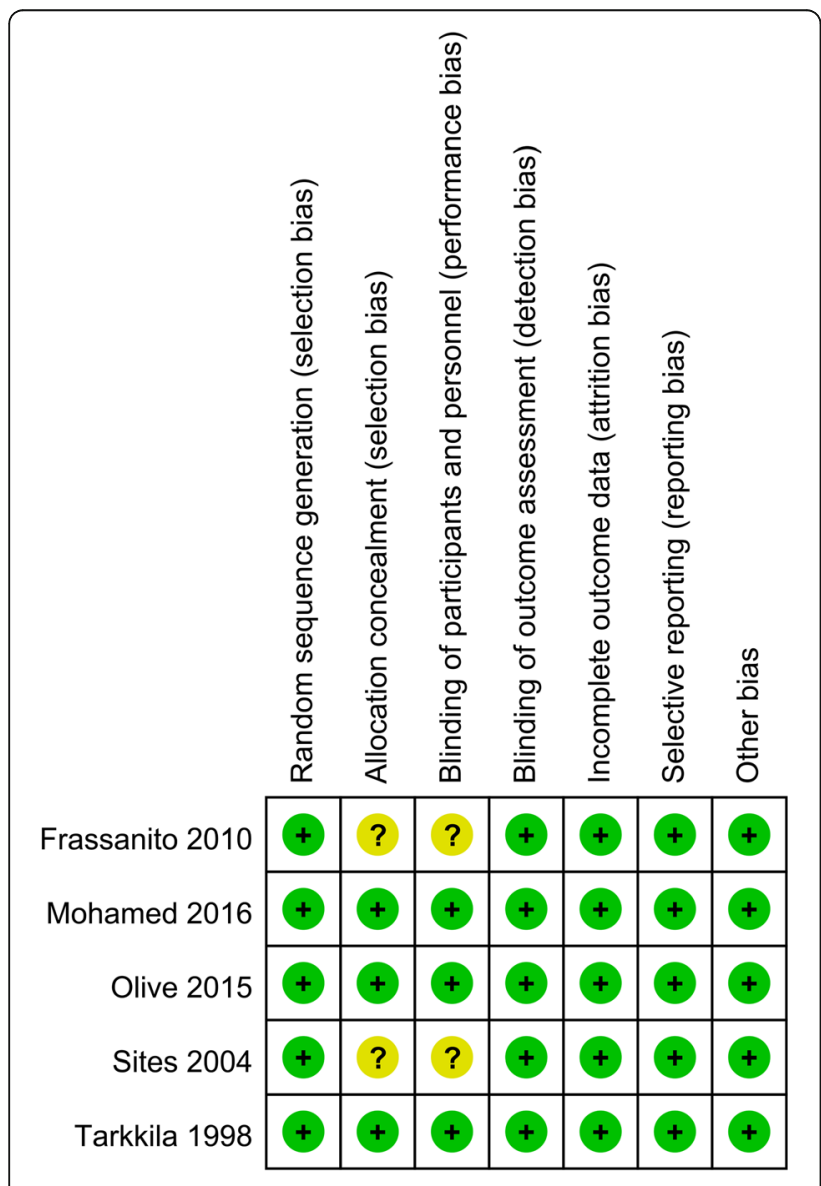

Fig. 2 The risk of bias graph
$-0.89, P=0.006$, Fig. 4) when compared with the FNB group. Postoperative VAS scores at $6 \mathrm{~h}$ in the included studies had a large heterogeneity $\left(I^{2}=88.8 \%, P=0.000\right)$, which required a random-effects model that was performed to analyse the data.

The meta-analysis results indicated that ITM can decrease VAS scores at $12 \mathrm{~h}$ (WMD $=-9.90,95 \% \mathrm{CI}$ $-15.05,-4.74, P=0.000$, Fig. 4) when compared with the FNB group. Postoperative VAS scores at $12 \mathrm{~h}$ in the included studies had a large heterogeneity $\left(I^{2}=74.9 \%\right.$, $P=0.003)$, which required a random-effects model that was performed to analyse the relevant data.

The results of the meta-analysis indicated that ITM can decrease VAS scores at $24 \mathrm{~h}$ (WMD $=-10.27,95 \%$ CI $-12.16,-8.39, P=0.001$, Fig. 4 ) when compared with the FNB group. Postoperative VAS scores at $24 \mathrm{~h}$ in the included studies had a large heterogeneity $\left(I^{2}=84.7 \%\right.$, $P=0.000)$, which required a random-effects model that was performed to analyse the relevant data.

The results of the meta-analysis indicated that ITM can decrease VAS scores at $48 \mathrm{~h}$ (WMD $=-10.27,95 \%$ CI $-12.16,-8.39, P=0.000$, Fig. 4) compared with the FNB group. Postoperative VAS scores at $48 \mathrm{~h}$ in the included studies had little heterogeneity $\left(I^{2}=24.7 \%\right.$, $P=0.249$ ).

The results of the meta-analysis indicated that ITM can decrease VAS scores at $72 \mathrm{~h}$ (WMD $=-9.00,95 \% \mathrm{CI}$ $-10.39,-7.61, P=0.000$, Fig. 4) when compared with the FNB group.

Total morphine consumption at 12, 24 and $48 \mathrm{~h}$

Total morphine consumption was presented in six studies. The pooled results indicated that ITM can reduce total morphine consumption at $12 \mathrm{~h}(\mathrm{WMD}=-1.17$, 95\% CI $-1.61,-0.73, P=0.000$, Fig. 5), $24 \mathrm{~h}$ $(\mathrm{WMD}=-3.96,95 \% \mathrm{CI}-4.43,-3.48, P=0.000$, Fig. 5$)$ and $48 \mathrm{~h}$ (WMD $=-2.76,95 \% \mathrm{CI}-3.72,-1.80$, $P=0.000$, Fig. 5).

\section{The occurrence of PONV}

There were no significant differences between the groups in the occurrence of PONV ( $R R=1.10,95 \%$ CI 0.57, 2.12, $P=0.769$, Fig. 6). There was high heterogeneity between the included studies $\left(I^{2}=76.5 \%, P=0.005\right)$, and thus, a random-effect model was performed.

\section{The occurrence of itching}

The occurrence of itching was presented in three studies. Compared with the FNB group, ITM was associated with an increase of the occurrence of itching $(R R=2.50$, 95\% CI 1.05, 5.93, $P=0.038$, Fig. 7). There was a high heterogeneity $\left(I^{2}=61.8 \%, P=0.073\right)$ among the included studies, and thus, a random-effects model was performed. 


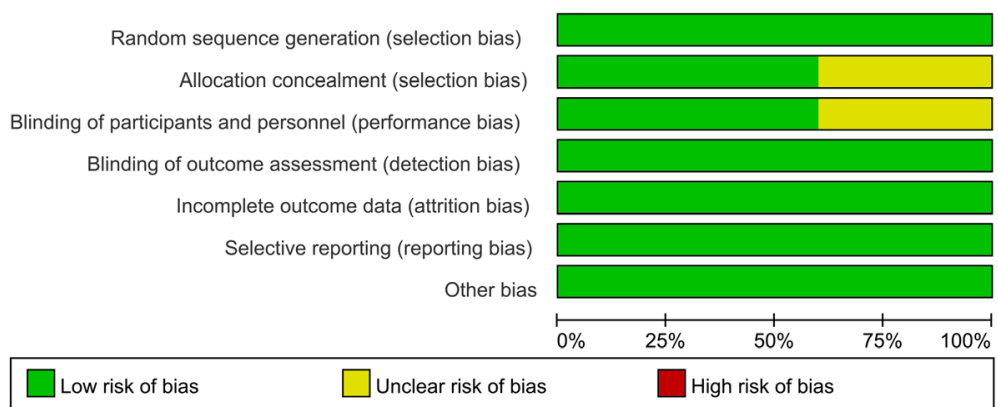

Fig. 3 Risk of bias summary of included randomized controlled trials. +, no bias; -, bias;?, bias unknown

\section{Subgroup analysis and dose-response relationship}

Subgroup analysis was conducted according to the type of FNB (CFNB or SFNB). The results are shown in Additional file 1 and indicate that there was no significant difference between the CFNB and SFNB in terms of VAS at 6,12 and $24 \mathrm{~h}$.

\section{Discussion}

This meta-analysis aimed to illustrate the optimal method of pain control in TKA patients using ITM and FNB. Pooled results indicated that the ITM group had lower pain scores at $6,12,24,48$ and $72 \mathrm{~h}$ after TKA.
Furthermore, ITM was associated with less total morphine consumption at 12,24 and $48 \mathrm{~h}$ after TKA. However, ITM was associated with an increase of the occurrence of itching. There was no significant difference in the occurrence of PONV after TKA. A major strength of this meta-analysis was that we comprehensively searched the electronic databases and used a rigorous statistical calculation. A total of five relevant studies were included, and the risk of bias was relatively high.

TKA is characterized by severe postoperative pain and morphine-related complications. A meta-analysis has identified that the administration of FNB was associated

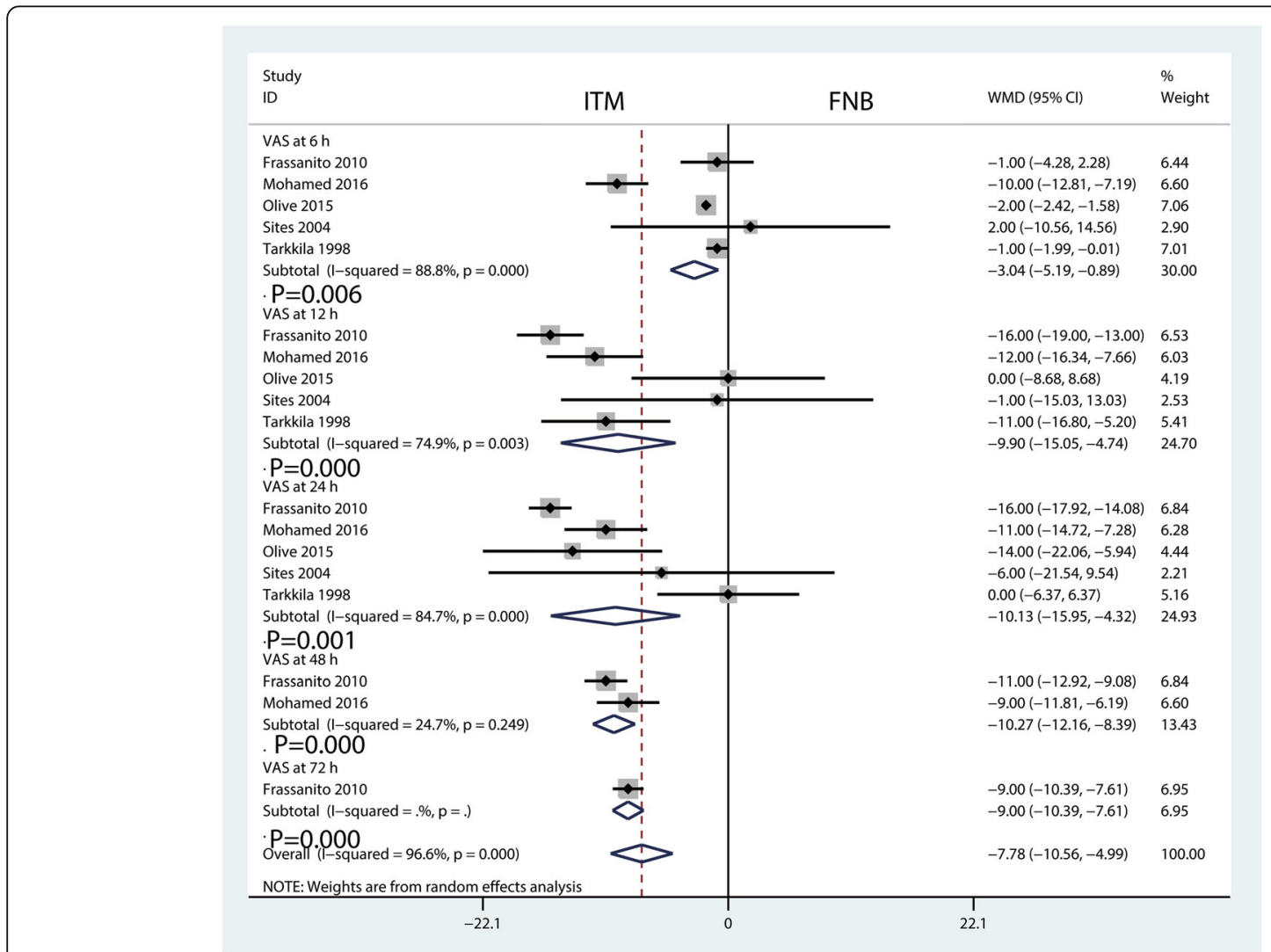

Fig. 4 Forest plots of the included studies comparing the VAS at 6, 12, 24, 48 and $72 \mathrm{~h}$ 


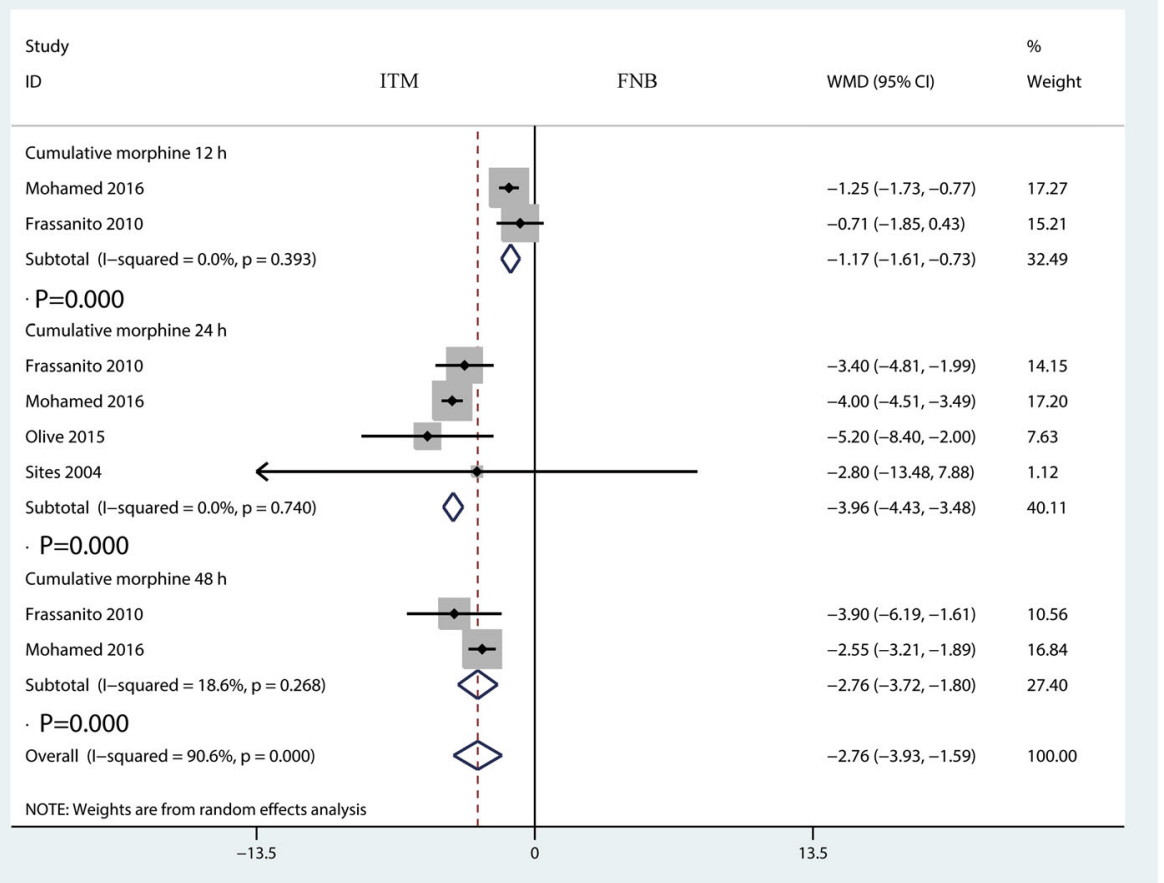

Fig. 5 Forest plots of the included studies comparing the total morphine consumption at 12, 24 and 48h

with a reduction in pain intensity after TKA [5]. FNB has been identified as an effective method for decreasing postoperative pain and morphine consumption after TKA. Alternatively, there is solid evidence supporting the use of ITM $[16,17]$. Currently, there is no consensus regarding which methods are more effective after TKA surgery. Thus, we performed this meta-analysis to provide summary evidence for surgeons for a better choice of pain control following TKA. The current meta-analysis indicated that ITM was more effective than FNB at 6,12 , 24,48 and $72 \mathrm{~h}$ after TKA. The doses of ITM ranged from 0.1 to $0.5 \mathrm{mg}$ [18]. A meta-analysis showed that the rate of episodes of respiratory depression (doses $<0.3 \mathrm{mg}$ ) was equal to that of the systemic opioids group [19]. The dose of morphine in the ITM group in the meta-analysis ranged from 0.1 to $0.3 \mathrm{mg}$, and this may be due to heterogeneity

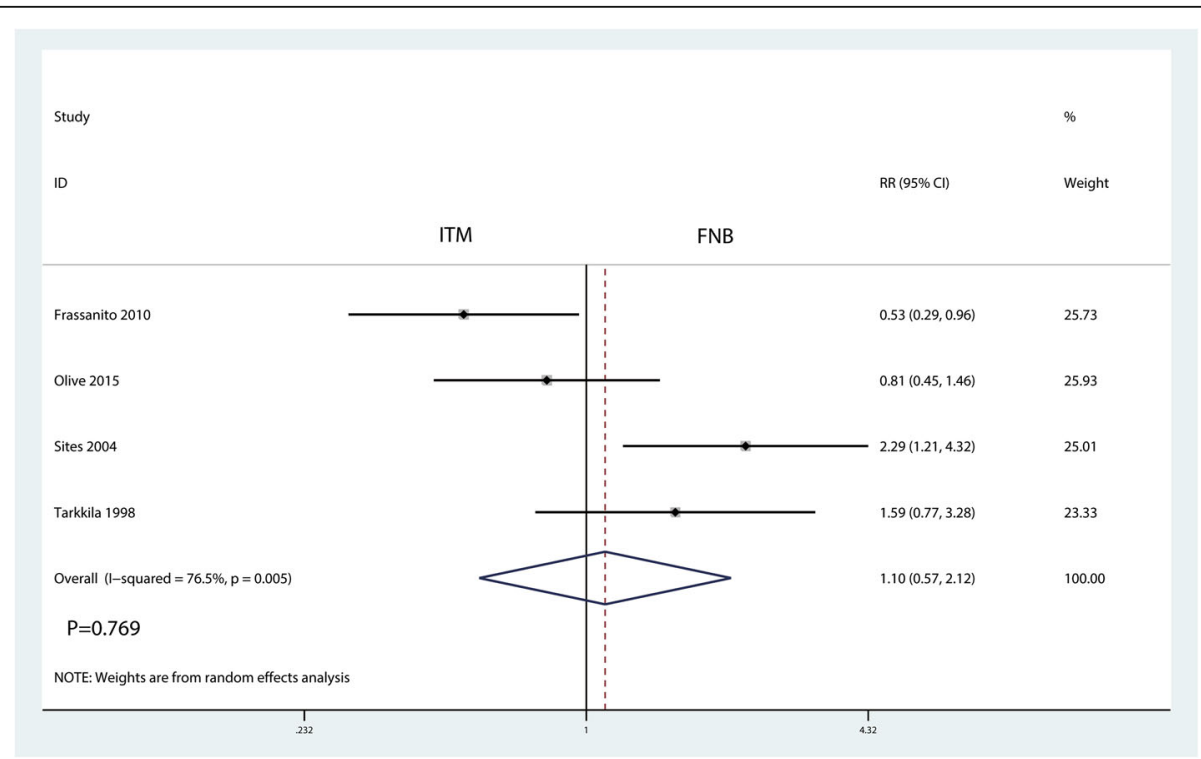

Fig. 6 Forest plots of the included studies comparing the occurrence of PONV 


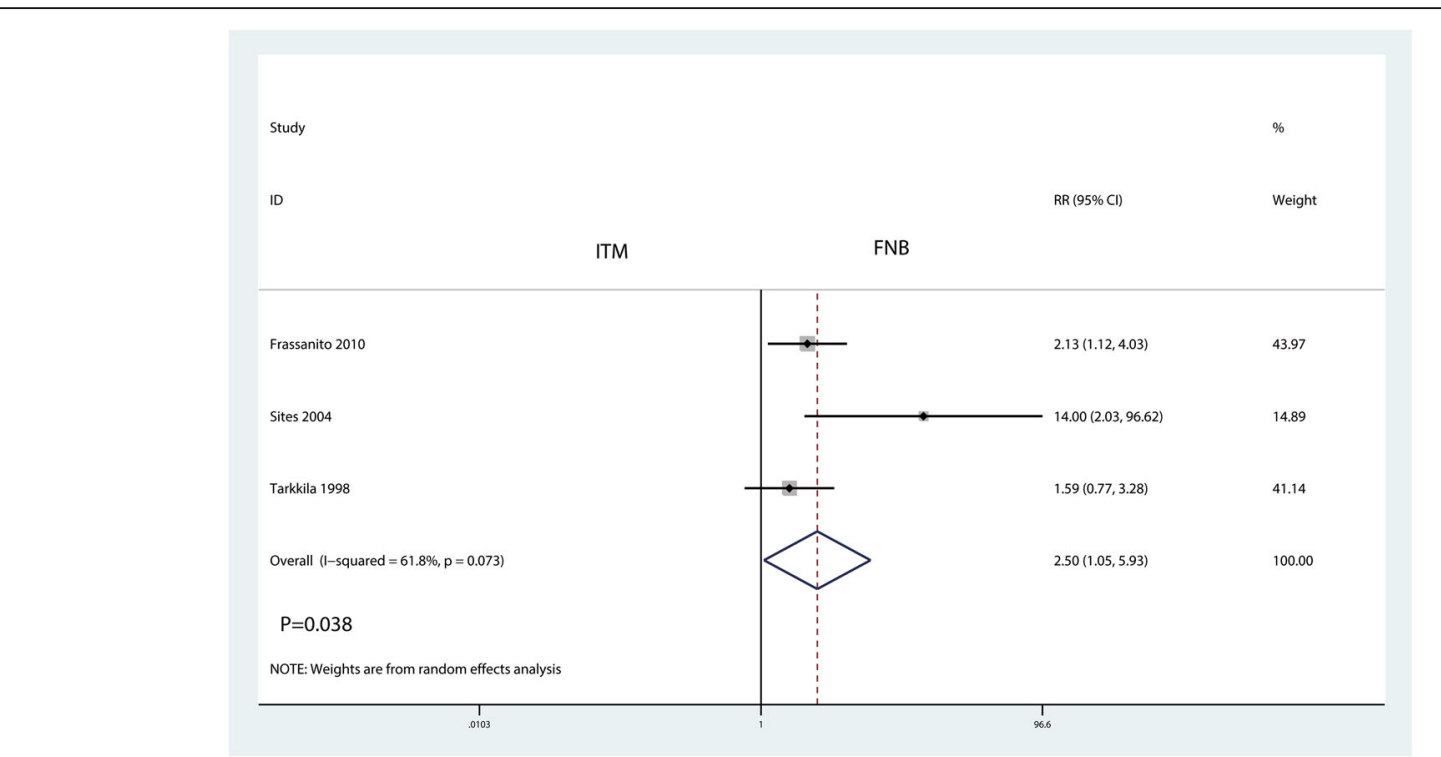

Fig. 7 Forest plots of the included studies comparing the occurrence of itching

in the sources of different studies. Meanwhile, two studies performed the CFNB, and the remaining three studies performed the SFNB.

Since pain intensity was decreased in the ITM group, morphine consumption as a supplement for pain control was decreased correspondingly. Pooled results indicated that the ITM group was associated with a reduction of total morphine consumption at $12 \mathrm{~h}$ by $1.17 \mathrm{mg}$ $(\mathrm{WMD}=-1.17,95 \% \mathrm{CI}-1.61,-0.73, P=0.000)$ and $3.96 \mathrm{mg}$ at $24 \mathrm{~h}$ (WMD $=-3.96,95 \% \mathrm{CI}-4.43,-3.48$, $P=0.000)$ and $48 \mathrm{~h}(\mathrm{WMD}=-2.76,95 \% \mathrm{CI}-3.72$, $-1.80, P=0.000)$. Li et al. [7] found that total morphine consumption in the ITM group was less than in the FNB group, at appropriately $0.84 \mathrm{mg}$. Chang et al. [20] reported that the addition of IT morphine $0.1 \mathrm{mg}$ to continuous femoral 3-in-1 nerve block improves postoperative analgesia and morphine consumption after TKA.

Another issue that must be addressed is that FNB requires the use of an ultrasound machine and a special needle, which add to the cost. Additionally, another anaesthetist is needed to perform FNB, and thus, it may add to the total operation time. In this regard, ITM is very cost effective, time-saving and a relatively simple technique.

There were a total of six limitations in this metaanalysis: (1) only five RCTs were included, which may have affected the precision of the effect size estimations; (2) follow-up in the included studies ranged from $24 \mathrm{~h}$ to 6 months, and the relatively short-term follow-up may underestimate the complication rate; (3) the dosage of ITM differed between the studies, and although a subgroup analysis was conducted to decrease heterogeneity, that could affect the precision of the results; (4) the dosage, drugs and type of FNB differed between the studies, which could affect the precision of the results; (5) multiple analgesic approaches differed from one another, and consistent multiple analgesic approaches are needed to identify the most effective pain control method; and (6) publication bias was not performed due to the limited number of included studies, and there was potential publication bias.

\section{Conclusion}

In conclusion, some immediate analgesic efficacy and opioid-sparing effects were obtained with the administration of ITM when compared with FNB. Complications of itching in the ITM group were greater than in the FNB group. Because the sample size and the number of included studies were limited, a multi-centre RCT is needed to identify the effects of ITM in reducing acute pain following TKA surgery.

\section{Additional file}

Additional file 1: Subgroup analysis results of VAS score. (DOCX $6040 \mathrm{~kb}$ )

\section{Abbreviations}

CFNB: Continuous femoral nerve block; Cl: Confidence interval; DVT: Deep venous thrombosis; FNB: Femoral nerve block; ITM: Intrathecal morphine; NRS: Numerical rating scale; PONV: Postoperative nausea and vomiting; PRISMA: Preferred Reporting Items for Systematic Reviews and Meta-analyses; RCTs: Randomized controlled trials; RR: Relative risk; SD: Standard deviation; SFNB: Single shot femoral nerve block; TKA: Total knee arthroplasty; VAS: Visual analogue scale; WMD: Weight mean difference

\section{Acknowledgements}

We thank Aaberish, Dong Lin and Yong-long Liu for searching the French, German, Spanish and Italian literatures. 


\section{Funding}

There is no funding for this article.

\section{Availability of data and materials}

We state that the data will not be shared since all the raw data are present in the figures included in the article.

\section{Authors' contributions}

TY and XT conceived the study design. QHW and $\mathrm{HZ}$ performed the study, collected the data and contributed to the study design. TY and QHW prepared the manuscript. $\mathrm{HZ}$ and TY edited the manuscript. All authors read and approved the final manuscript.

\section{Ethics approval and consent to participate}

None

\section{Consent for publication}

Not applicable.

\section{Competing interests}

The authors declare that they have no competing interests.

\section{Publisher's Note}

Springer Nature remains neutral with regard to jurisdictional claims in published maps and institutional affiliations.

Received: 5 April 2017 Accepted: 18 July 2017

Published online: 16 August 2017

\section{References}

1. Keijsers $R$, van den Bekerom M, van Delft R, van Lotten M, Rademakers M, Nolte PA. Continuous local infiltration analgesia after TKA: a meta-analysis. J Knee Surg. 2016;29(4):310-21.

2. Sun $X L$, Zhao $Z H, M a ~ J X$, et al. Continuous local infiltration analgesia for pain control after total knee arthroplasty: a meta-analysis of randomized controlled trials. Medicine (Baltimore). 2015;94(45):e2005.

3. Dong J, Li W, Wang Y. The effect of pregabalin on acute postoperative pain in patients undergoing total knee arthroplasty: a meta-analysis. Int J Surg. 2016;34:148-60.

4. Kehlet $\mathrm{H}$, Holte $\mathrm{K}$. Effect of postoperative analgesia on surgical outcome. $\mathrm{Br}$ J Anaesth. 2001;87(1):62-72.

5. Chan EY, Fransen M, Parker DA, Assam PN, Chua N. Femoral nerve blocks for acute postoperative pain after knee replacement surgery. Cochrane Database Syst Rev. 2014;13(5):Cd009941.

6. Fischer HB, Simanski CJ, Sharp C, et al. A procedure-specific systematic review and consensus recommendations for postoperative analgesia following total knee arthroplasty. Anaesthesia. 2008;63(10):1105-23.

7. Li XM, Huang CM, Zhong CF. Intrathecal morphine verse femoral nerve block for pain control in total knee arthroplasty: a meta-analysis from randomized control trials. Int J Surg. 2016;32:89-98.

8. Mohamed, A. A., Maghraby, H. H., Abdelghaffar, H. S. Comparison of combined intrathecal morphine and sonar-guided single shot femoral nerve block vs. either technique alone for postoperative analgesia in patients undergoing total knee replacement surgery. (2016).

9. Liberati A, Altman DG, Tetzlaff J, et al. The PRISMA statement for reporting systematic reviews and meta-analyses of studies that evaluate healthcare interventions: explanation and elaboration. BMJ. 2009;339:b2700.

10. Wang C, Cai X-Z, Yan S-G. Comparison of periarticular multimodal drug injection and femoral nerve block for postoperative pain management in total knee arthroplasty: a systematic review and meta-analysis. The Journal of arthroplasty. 2015;30(7):1281-6.

11. GS, H. J. Cochrane handbook for systematic reviews of interventions version 5.1.0. [http://handbook.cochrane.org/]. Accessed 2011.

12. Frassanito L, Vergari A, Zanghi F, Messina A, Bitondo M, Antonelli M. Post-operative analgesia following total knee arthroplasty: comparison of low-dose intrathecal morphine and single-shot ultrasound-guided femoral nerve block: a randomized, single blinded, controlled study. Eur Rev Med Pharmacol Sci. 2010;14(7):589-96.

13. Olive DJ, Barrington MJ, Simone SA, Kluger R. A randomised controlled trial comparing three analgesia regimens following total knee joint replacement: continuous femoral nerve block, intrathecal morphine or both. Anaesth Intensive Care. 2015;43(4):454-60.
14. Sites BD, Beach M, Gallagher JD, Jarrett RA, Sparks MB, Lundberg CJ. A single injection ultrasound-assisted femoral nerve block provides side effect-sparing analgesia when compared with intrathecal morphine in patients undergoing total knee arthroplasty. Anesth Analg. 2004;99(5):1539-43. table of contents

15. Tarkkila P, Tuominen M, Huhtala J, Lindgren L. Comparison of intrathecal morphine and continuous femoral 3-in-1 block for pain after major knee surgery under spinal anaesthesia. Eur J Anaesthesiol. 1998;15(1):6-9.

16. Karlsen AP, Wetterslev M, Hansen SE, Hansen MS, Mathiesen O, Dahl JB. Postoperative pain treatment after total knee arthroplasty: a systematic review. PLoS One. 2017;12(3):e0173107.

17. Kilickaya R, Orak Y, Balci MA, Balci F, Unal I. Comparison of the effects of intrathecal fentanyl and intrathecal morphine on pain in elective total knee replacement surgery. Pain Res Manag. 2016;2016:3256583.

18. Mugabure Bujedo B. A clinical approach to neuraxial morphine for the treatment of postoperative pain. Pain Res Treat. 2012;2012:612145.

19. Gehling M, Tryba M. Risks and side-effects of intrathecal morphine combined with spinal anaesthesia: a meta-analysis. Anaesthesia. 2009;64(6):643-51.

20. Chang KP, Cho $\mathrm{CK}$, Shin $\mathrm{HH}$, Cho JH. The effect of intrathecal morphine added to continuous femoral 3-in-1 nerve block for analgesia after total knee replacement. Korean Journal of Anesthesiology. 2008;54(5):544-51.

\section{Submit your next manuscript to BioMed Central and we will help you at every step:}

- We accept pre-submission inquiries

- Our selector tool helps you to find the most relevant journal

- We provide round the clock customer support

- Convenient online submission

- Thorough peer review

- Inclusion in PubMed and all major indexing services

- Maximum visibility for your research

Submit your manuscript at www.biomedcentral.com/submit
Biomed Central 